\section{Commentary: Stay midline, stay steady: Median sternotomy training}

\author{
Neel R. Sodha, MD
}

I vividly remember performing my first median sternotomy as a general surgery intern. The room was busy, the music was loud. The attending surgeon peered over the drape, nodded his head toward me, and signaled to the fellow to give me the saw. My only instruction: Stay midline, stay steady. Although it is the most commonly used approach in cardiac surgery, performing a so-called good sternotomy is often an afterthought. Trainees generally acquire the skill in the operating room on actual patients. Considered a basic skill, a poorly performed median sternotomy can result in significant complications. ${ }^{1}$ Recognizing an opportunity for an adjunct educational tool, and spurred by significant support from educators and program directors in Canada, Vo and colleagues ${ }^{2}$ have developed a simulation model for the practice of median sternotomy and provide preliminary validation evidence for its use in training.

Trehan and colleagues ${ }^{3}$ have recently reviewed cardiothoracic surgical simulation. Although there are excellent models for techniques such as vascular anastomosis or cannulation for cardiopulmonary bypass, the median sternotomy is often neglected. A major strength of the study by Vo and colleagues ${ }^{2}$ is that they have developed an inexpensive, realistic model focusing on performing this important task. The model is easy to reproduce, and blinded assessments by participants indicate they found the model to

\footnotetext{
From the Division of Cardiac Surgery, Alpert Medical School, Brown University, Providence, RI

Disclosures: The author reported no conflicts of interest.

The Journal policy requires editors and reviewers to disclose conflicts of interest and to decline handling or reviewing manuscripts for which they may have a conflict of interest. The editors and reviewers of this article have no conflicts of interest.

Received for publication Feb 25, 2020; revisions received Feb 25, 2020; accepted for publication Feb 29, 2020; available ahead of print April 1, 2020.

Address for reprints: Neel R. Sodha, MD, Division of Cardiac Surgery, Alpert Medical School, Brown University, 2 Dudley St, MOC Suite 360, Providence, RI 02905 (E-mail: nsodha@lifespan.org).

JTCVS Techniques 2020;2:117-8

2666-2507

Copyright (C) 2020 The Authors. Published by Elsevier Inc. on behalf of The American Association for Thoracic Surgery. This is an open access article under the CC BY-NCND license (http://creativecommons.org/licenses/by-nc-nd/4.0/).

https://doi.org/10.1016/j.xjtc.2020.02.035
}

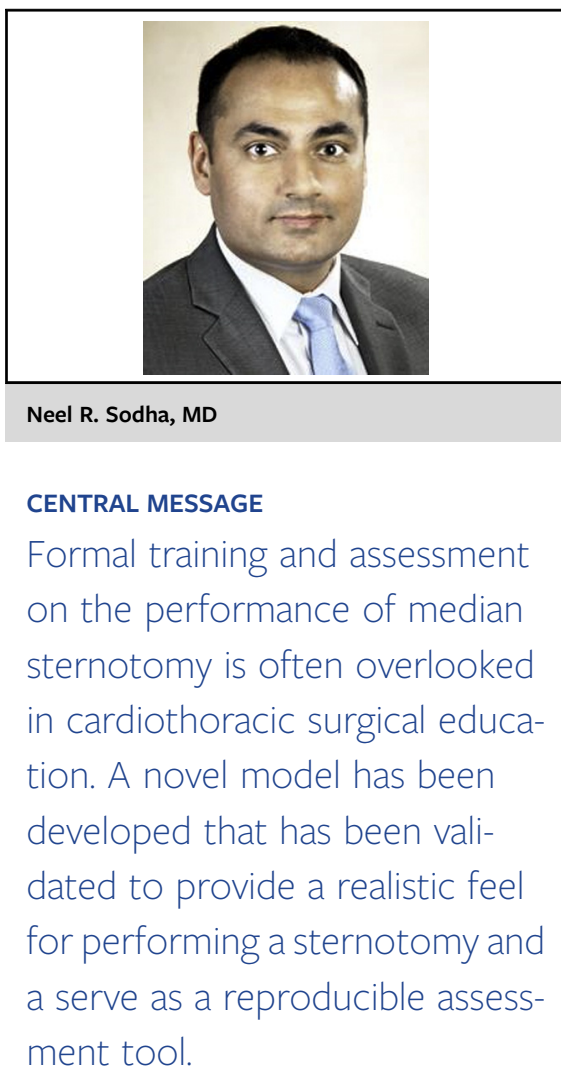

be realistic and useful. The checklist developed for the model served not only to elucidate the basic steps in performing a sternotomy, but also highlighted the importance of areas such as communication. In addition to serving as a training tool, the checklist developed by the authors also serves as a tool for assessment, allowing for incorporation of the model into a competency-based educational curriculum.

While providing a new tool for training and competency assessment, the study does have a few limitations which the authors acknowledge. The sample size of 13 participants is small and nearly one-third had performed 10 or more sternotomies before participating in the study. Due to logistical constraints, the sample size could not be increased for the current article. Additionally, participants were junior trainees in the Canadian training system where cardiac surgical training begins at the completion of medical school, rather than after general surgery training, as is common in the United States. Whether more advanced trainees would find as much utility in the model is unclear. Lastly, the interrater reliability for assessment on the checklist was 
suboptimal, raising some questions as to the validity of the checklist as a good metric for assessment.

Patients recognize the importance of a median sternotomy, often having more questions about having their chest cracked open than how the bypass is done or how the valve is sewn in place. As educators, we should ensure we pay as much attention to opening the chest as patients do.

\section{References}

1. Zeitani J, Penta de Peppo A, Moscarelli M, Guerrieri Wolf L, Scafuri A, Nardi P, et al. Influence of sternal size and 362 inadvertent paramedian sternotomy on stability of the closure site: a clinical and 363 mechanical study. J Thorac Cardiovasc Surg. 2006;132:38-42.

2. Vo TX, Juanda N, Ngu J, Gawad N, LaBelle K, Rubens FD. Development of a median sternotomy simulation model for cardiac surgery training. J Thorac Cardiovasc Surg Tech. 2020;2:109-16.

3. Trehan K, Kemp CD, Yang SC. Simulation in cardiothoracic surgical training: where do we stand? J Thorac Cardiovasc Surg. 2014;147:18-24. 